\title{
Lowering the sink temperature for a desert solar air conditioning system
}

\author{
M. A. Serag-Eldin \\ American University in Cairo, Egypt
}

\begin{abstract}
The paper addresses the problem of cooling air conditioning systems in desert environments where ambient air temperatures are high, and cooling towers should be avoided because of scarcity of water resources. A proposed ground heat-sink is proposed which exploits the highly effective night-time desert cooling by long-wave atmospheric radiation. A simple computer model is presented for the performance of the heat-sink design, which integrates with a load calculation model for a hypothetical zero energy house, in which the air conditioning equipment is solar driven. The load-calculation and thermal-sink models are matched dynamically with the time dependent solar energy characteristics of the selected site, and predicted results are displayed and discussed.
\end{abstract}

Keywords: solar air-conditioning, ZEH, renewable energy, geothermal cooling, heat sinks, COP.

\section{Introduction}

Modern designs for desert Zero energy houses (ZEH) provide all modern comforts, relying on solar energy as the energy source to power the homes energy needs. By far the largest energy load for this environment is the air conditioning load, e.g. Serag-Eldin [1]. Air-conditioning equipment performance is affected heavily by the heat-sink (condenser) temperature, the higher the latter the lower the COP; indeed above a certain temperature the equipment mal-functions and may shut-down altogether to protect itself. Cooling the condenser requires dissipating the heat to a lower temperature environment. The two common methods of cooling are air cooling by atmospheric air (releasing heat to the environment directly) and water cooling by circulating 
water which releases its heat to the environment indirectly through cooling ponds and cooling towers. A third, but unconventional method, employs geothermal cooling, e.g. Yasukawa et al. [2] and Permchart and Tanatvanit [3].

Air cooling is not always effective in a desert environment, since the ambient temperatures often exceed the allowable condenser temperatures during sunshine hours; reaching $50^{\circ} \mathrm{C}$ in some places. Water cooling using cooling ponds and towers consumes too much water in the form of evaporation; this should not be allowed in a desert environment where water is scarce. Geothermal cooling could be highly expensive for large capacity equipment, requiring long lengths of pipes and ground area; moreover it necessitates a low ground temperature to be effective, which is not always the case; for e.g. in KSA the annual average soil temperature is around $31^{\circ} \mathrm{C}$ and could be considerably higher close to the surface in summer.

The present paper presents a conceptual heat-sink design which is believed to be better suited to the desert climate. The design is first presented, followed by a brief description of the models employed to evaluate it, and by a demonstration of their application to a $\mathrm{ZEH}$.

\section{Proposed conceptual design}

It is proposed here to cool the air-conditioning system condenser employing cooling-water circulating in a closed loop. For a given condenser temperature, $\mathrm{T}_{\text {cond }}$, the maximum cooling water inlet temperature, $\mathrm{T}_{\mathrm{cwi}}$, and cooling water outlet temperature, $\mathrm{T}_{\mathrm{cwo}}$, are all fixed by controlling the water flow rate. Three alternate cooling operation modes are available; the mode employed depending on the ambient air temperature $\mathrm{T}_{\mathrm{a}}$, as follows:

i) $\quad \underline{T}_{\underline{a}}<T_{c w i}-5^{\circ} \underline{C}$ :

cooling water is totally air-cooled in a cross-flow heat exchanger, prior to returning to condenser.

ii) $\quad \underline{T}_{\underline{a}}>T_{c w i}-5^{\circ} \underline{C}$, but $\underline{T}_{a}<T_{c w i}$ : cooling water is first air-cooled to a temperature $=\mathrm{T}_{\mathrm{cwo}}-\left(\mathrm{T}_{\mathrm{cwo}}\right.$ $\left.\mathrm{T}_{\mathrm{cwi}}\right)\left(\mathrm{T}_{\mathrm{cwi}}-\mathrm{T}_{\mathrm{a}}\right) / 5^{\circ} \mathrm{C}$, after which it passes to a ground heat sink where it is further cooled to the desired $\mathrm{T}_{\text {cwi }}$.

iii) $\quad \underline{T}_{\underline{a}}>T_{\text {cwi }}$ :

cooling water is directed straight to the ground heat-sink at a temperature of $\mathrm{T}_{\mathrm{cwo}}$, flowing through a well insulated pipe.

Hence air cooling is invoked whenever it is feasible to do so, either partially or entirely, thus reducing the load on the ground heat-sink. The proposed sink is simply a dug-in, long, shallow, and narrow trench of rectangular cross-section, whose sides are first thermally insulated, and subsequently filled with the same excavated ground material (assumed sand). Buried at its centre are longitudinally laid finned ducts, through which the cooling water flows. The sides of the ground sink are thermally insulated to reduce heat losses. A removable cover (either hinged or sliding) is used to cover the sink surface 
during sunshine hours. The cover is made of $2.5 \mathrm{cms}$ thick softwood, covered by thin commercial aluminium sheets on each side. When present, the cover is lifted approximately $0.01 \mathrm{~m}$ above the sink surface by peripheral wooden spacers.

During sun shine hours, the ground sink is covered and therefore most $(\sim 80 \%)$ of the short wave solar radiation landing on the top surface is reflected back to the atmosphere. The relatively low emissivity (18\%) of aluminium cladding of the cover bottom reduces the long wave radiation exchange between the cover bottom and sink surface. The air gap provides cheap and excellent insulation properties to reduce heat conduction from cover to ground. Since gap height is small, and the hotter surface is the top one, convective effects (all natural) are negligible.

After sunset and until next day sunrise, the sink surface is exposed directly to the night sky, which in desert environments is considerably cooler than the ambient air. Thus appreciable net cooling of the sink occurs through long wave (infra red) radiation exchange with sky; convective cooling/heating may also sometimes be significant, depending on wind conditions and ambient temperatures. The latter are typically $10^{\circ} \mathrm{C}$ or more lower than daytime temperatures in the desert.

The naturally existing local soil achieves equilibrium temperatures which reflect the balance between day time heating, night time cooling and ground storage within the thermal penetration depth. Therefore the ground sink, by substantially reducing the daytime heat gain, while retaining the same night-time cooling, achieves lower equilibrium temperatures as revealed in coming sections. Thus the theory of its operation. Side insulation is introduced to eliminate heat seepage from surrounding uncovered ground.

\section{Mathematical models}

In previous work, Serag-Eldin [4] presented a mathematical model for predicting the cooling loads in a zero energy house. It comprised solar radiation models, coupled with time dependent heat conduction models and long wave atmospheric radiation models. The results employed measured environmental data reported by ASHRAE [5], for a hypothetical site in Dharan, KSA; a modern electronic expansion valve COP characteristic, Chinnaraj and Govindarajan [6] was adopted.

In the present work, the same load-calculation model is used to calculate the cooling loads on June $21^{\text {st }}$, the supposedly hottest day of the year, and for the same site. Figure 1 reveals the cooling load distribution on that day. The latter is the input to the ground-sink model presented here.

The heat-sink model includes a time dependent heat conduction model described by the following governing equation:

$$
\frac{\partial}{\partial t}(\rho c T)=\frac{\partial}{\partial x}\left(k \frac{\partial T}{\partial x}\right)
$$




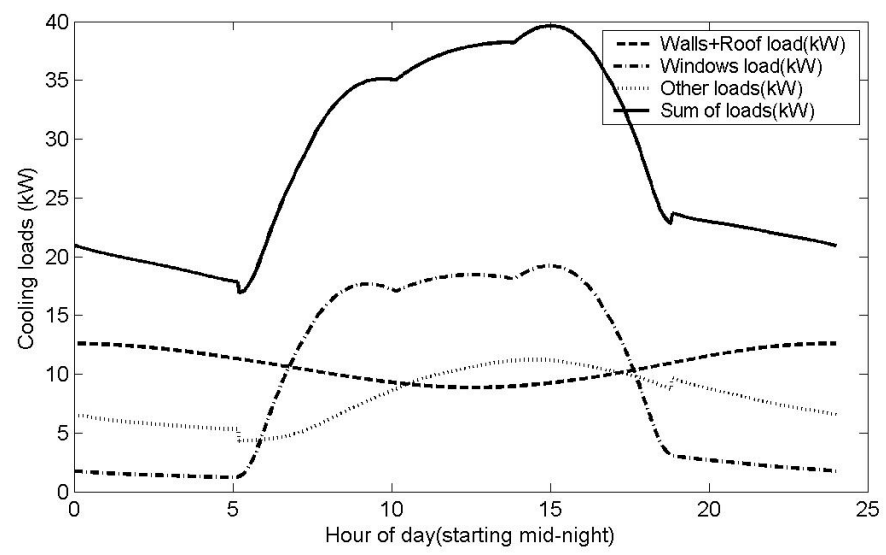

Figure 1: Cooling loads for ZEH on June $21^{\text {st }}$.

where $\mathrm{x}$ is the downward distance measured from the top surface of the cover, and $\mathrm{t}$ denotes time; whereas $\mathrm{T}, \rho, \mathrm{k}$ and $\mathrm{c}$ are the local values of the static temperature, solid density, coefficient of conductivity, and specific heat, respectively. Temperature gradients in axial and lateral directions are expected to be small and therefore neglected. The above equation is integrated numerically over control volumes bridging the domain bounded by the cover top surface and the ground-sink bottom surface, employing the control-volume method.

In addition to the above terms, surface heat source terms, $\mathrm{S}_{\mathrm{h}}\left(\mathrm{W} / \mathrm{m}^{2}\right)$, are introduced at the following locations:

i) cover top surface(when present):

$$
S_{h}=\left(1-\rho_{s w_{-} c v}\right) q_{s o l}+h_{o}\left(T_{a}-T_{c v_{-} t o p}\right)+\varepsilon_{c v_{-} t p} \sigma\left(\varepsilon_{a} T_{a}^{4}-T_{c v_{-} t o p}^{4}\right)
$$

where $\rho_{\mathrm{sw}-\mathrm{cv}}$ is the short wave reflectivity of the cover cladding, $\mathrm{T}_{\mathrm{cv} \text {-top }}$ is the surface temperature of the cover top, $\varepsilon_{\mathrm{cv} \text {-top }}$ is the long wave emissivity of cover top and $\varepsilon_{\mathrm{a}}$ is the apparent emissivity of the atmosphere (Bliss [7] and ASHRAE [8]). $\quad \varepsilon_{\mathrm{a}}$ is defined as the ratio of the long wave atmospheric radiation on a horizontal surface per unit area to $\left(\sigma \mathrm{T}_{\mathrm{a}}{ }^{4}\right)$, and is only a function of the dew point temperature near ground; the latter is derived from instantaneous values of drybulb and wet bulb temperatures, as shown by Serag-Eldin [4] for cooling load calculations. $\mathrm{q}_{\mathrm{sol}}$ is the global solar radiation on a horizontal surface, and is calculated in same way as for load calculations. The convective heat transfer coefficient, $h_{o}$ is calculated from the following formula (Kreider et al. [9]):

$$
h_{o}=6.2\left(\frac{V^{4}}{L}\right)^{0.2}
$$


where the characteristic length $\mathrm{L}$ is taken as channel width, and a wind speed, $\mathrm{V}=3 \mathrm{~m} / \mathrm{s}$ is assumed.

ii) $\quad$ cover bottom surface (when present):

$$
S_{h}=\frac{\sigma\left(T_{s k}^{4}-T_{c v_{-} b o t}^{4}\right)}{\left(1 / \varepsilon_{c v_{-} b o t}+1 / \varepsilon_{s k}-1\right)}
$$

where the subscript 'sk' refers to sink surface, and $\varepsilon_{\mathrm{cv} \text {-bot }}$ refers to cover bottom emissivity. Forced convection is absent and free convection is ignored since gap thickness is small $(0.01 \mathrm{~m})$ and the hotter plate is the top one; however conduction heat transfer is retained across the air gap.

iii) ground-sink surface:

When cover is present $S_{h}$ is equal but opposite in sign to that of equation (4). However, when cover is absent the source term becomes:

$$
S_{h}=\left(1-\rho_{s w_{-} s k}\right) q_{s o l}+h_{o}\left(T_{a}-T_{s k}\right)+\varepsilon_{s k} \sigma\left(\varepsilon_{a} T_{a}^{4}-T_{s k}^{4}\right)
$$

where $\rho_{\text {sw-sk }}$ refers to short-wave reflectivity of the sink surface, and subscript 'sk' refers to sink surface properties.

iv) duct plane:

A source term is introduced at the control volume containing the cooling-water duct, representing the local heat transferred from cooling water to the sink per unit sink surface area, $\mathrm{q}_{\mathrm{L}}$. The latter is calculated from:

$$
q_{L}=\frac{\left(T_{c w, z}-T\right)}{\left(1 / h_{i} P+\Delta x / k P_{e f f}\right)}
$$

where $\mathrm{T}$ denotes the temperature of the sand surrounding the cooling-water duct, $\mathrm{T}_{\mathrm{cw}, \mathrm{z}}$ is the cooling-water bulk temperature at considered downstream location ' $\mathrm{Z}$ ', $\mathrm{P}$ is the perimeter of the internal walls of duct, $\mathrm{P}_{\text {eff }}$ is an effective perimeter (surface contact area per unit length) between cooling water and surrounding sand, whereas $\Delta \mathrm{x}$ represents the distance between the external surface of the duct and $\mathrm{T}$ node.

It is expected that the actual duct will be composed of several smaller ducts of same cross-sectional area, each displaying long horizontal fins; possibly covering the entire sink breadth so that heat dissipated can be conducted as uniformly as possible to sink surface. In the present work, the geometric details of the duct and fins are not considered; it is merely assumed that $\mathrm{P}_{\text {eff }}$ lies between an upper value equal to channel breadth, and a lower one equal to P, i.e. to case without fins. Unless otherwise stated, displayed results correspond to an intermediate value; however, effect of $\mathrm{P}_{\text {eff }}$ on results is reported. The perimeter $\mathrm{P}$ is calculated for a single duct of $0.1 \mathrm{~m}$ breadth and $0.01 \mathrm{~m}$ height. The 
temperature $\mathrm{T}$ is taken to be the mean of the calculated temperatures at the nodes immediately above and below the duct centreline. The internal duct heat transfer coefficient is calculated from the following empirical relation (Holman and White [10]):

$$
\frac{h_{i} d_{h}}{k}=0.023 R_{e}^{0.8} \operatorname{Pr}^{0.3}
$$

where $d_{h}$ is duct hydraulic mean diameter, $R_{e}$ denotes Reynold's numbers and $P r$ denotes Prandtl's number; all properties pertaining to cooling water at $\mathrm{T}_{\mathrm{cw}, \mathrm{z}}$.

It is noticed that conductive resistance across duct walls is neglected as it is estimated to be much smaller than that of the surrounding soil if duct walls are thin and manufactured from aluminium.

The cooling water temperature $T_{\mathrm{cw}, \mathrm{z}}$ varies along the length of the pipe, $\mathrm{z}$, according to the following relation:

$$
\frac{d T_{c w, z}}{d z}=\frac{-q_{L}}{\dot{m}_{c w} c}
$$

where $\dot{m}_{c w}$ is the mass flow rate of the cooling water per unit channel width, and $c$ is its specific heat. It is derived at any time step from the calculated total cooling loads $\mathrm{Q}_{\mathrm{L}}$ according to :

$$
\dot{m}_{c w}=\frac{Q_{L}}{c\left(T_{c w o}-T_{c w i}\right) W_{s k}}
$$

where $\mathrm{W}_{\mathrm{sk}}$ is the sink width; $\mathrm{W}_{\mathrm{sk}}=4 \mathrm{~m}$ for the demonstration case.

The solution procedure is as follows:

i) cooling loads are calculated using cooling load model.

ii) corresponding $\dot{m}_{c w}$ values are calculated from eqn. (9).

iii) heat conduction eqn. (1) is solved for first downstream location $z$, employing the Crank-Nicholson method, with $\mathrm{T}_{\mathrm{cw}, \mathrm{z}}$ set to temperature of cooling water upon entering heat-sink. Solution extends over all time steps covering entire day, assuming $24 \mathrm{hr}$ periodic conditions, yielding internal solid temperatures.

iv) local and instantaneous value of $\mathrm{q}_{1}$ are derived from eqn. (6).

v) Eqn. (8) is solved for the next downstream $T_{\mathrm{cw}, \mathrm{z}}$ employing the second order accurate mid-point method.

vi) steps iii) to $v$ ) are repeated for successive downstream sections, each step employing the exit $\mathrm{T}_{\mathrm{cw}, \mathrm{z}}$ temperature of the previous section.

vii) solution yields required duct length when $T_{c w, z}=T_{c w i}$. 


\section{Ground-sink without loading}

Figure 2 displays the computed sink temperature variation with time in absence of cooling-water flow, i.e. no load. It displays results for the top surface, middle surface (where the cooling-water duct passes) and the insulated bottom; the corresponding ambient temperature is added for comparison. It is noticed that the sink surface temperatures are considerably lower than ambient air temperature, and that the mid-plane and bottom plane temperatures are highly uniform. During the afternoon hours when cooling loads are near their peak, the ambient temperature is over $40^{\circ} \mathrm{C}$, whereas the mid-plane temperature is only $28^{\circ} \mathrm{C}$. The impact of removing the cover on the surface temperature is highly pronounced, which suggests that it may be advantageous to remove cover slightly before sunset and return it slightly after sunrise, solar radiation being weak during those periods.

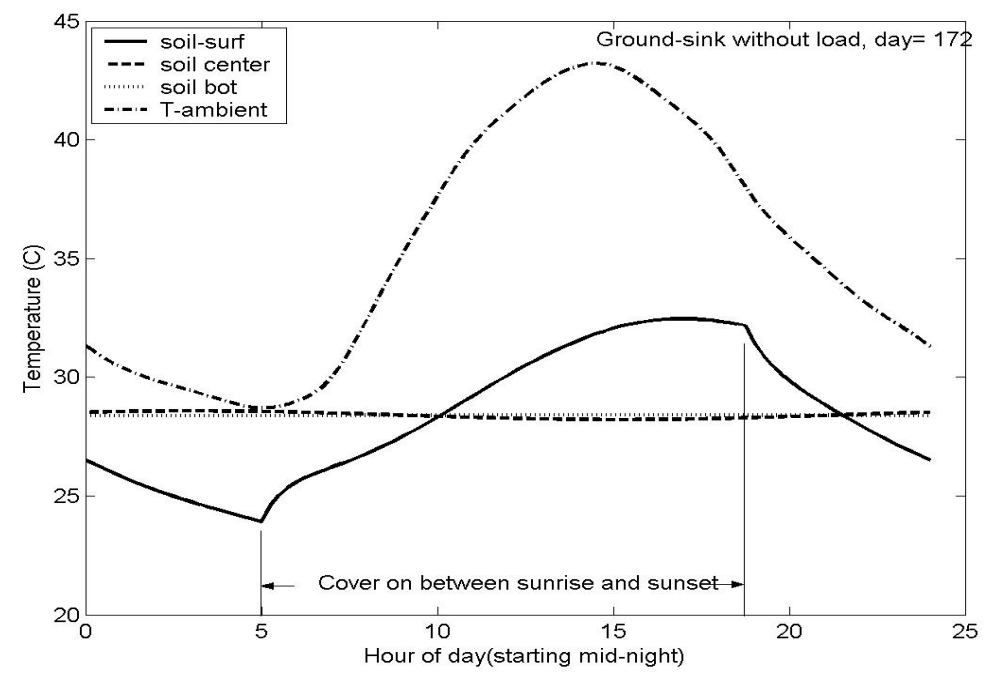

Figure 2: Daily variation of temperature at no load.

Figure 3 displays the corresponding temperature variation in the downward direction, measured from cover surface, at 6 hour intervals. The profile at midnight $(0 \mathrm{hr})$ is the only one without a cover; it therefore displays the ambient temperature in the location of the cover. It is noticed that at the outer surface of cover the surface temperature can exceed $50^{\circ} \mathrm{C}$ at solar noon, however those high temperatures are not transmitted inwards into the soil. The surface displays temperature fluctuations of the order of $7^{\circ} \mathrm{C}$, but those fluctuations are quickly diminished as we approach sink mid-plane, after which the temperature is almost uniform all the way to the bottom. 


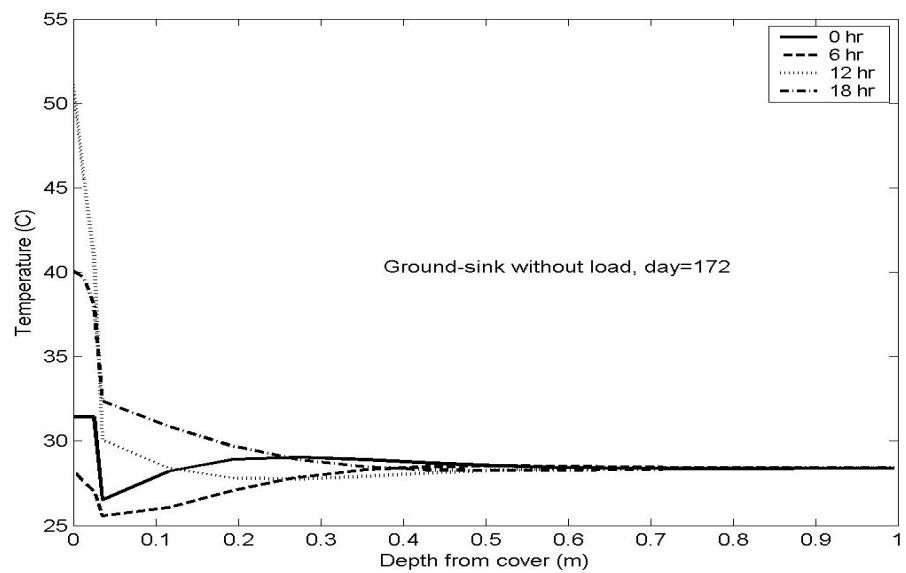

Figure 3: Variation with depth at various hours.

\section{Sink with heat dispersion}

Figure 4 displays the distribution of heat dispersion per unit area along the duct axis at near inlet section $(1 \mathrm{~m})$, and at downstream distances of $31 \mathrm{~m}, 81 \mathrm{~m}$ and $286 \mathrm{~m}$, respectively, the last section being close to outlet. As expected, $\mathrm{q}_{1}$ decreases downstream since $\mathrm{T}_{\mathrm{cw}}$ decreases and hence temperature difference between cooling water and surroundings decreases. It is noticed that when the cooling water first flows into the duct the sink is still cool and therefore the temperature difference is large causing rapid cooling, explaining the spike at inlet then. This rapid inlet cooling implies that the cooling water temperature will be considerably lower far downstream, causing the temperature difference to be small, thus explaining the lower $\mathrm{q}_{1}$ at inlet.

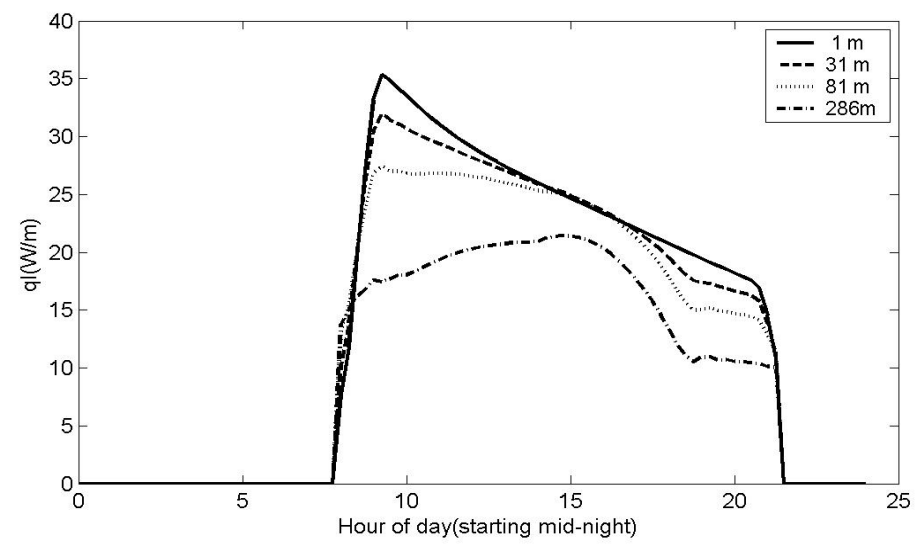

Figure 4: Hourly heat dispersion per m length. 
Figures 5 and 6 display the hourly variation of sink temperatures at near cooling-ware inlet and exit sections, respectively. It is noticed that the soil temperatures are higher near inlet because of the higher cooling water temperature at inlet. However, even at exit, the sink temperatures are still considerably higher than when there is no loading, Fig. 2. The mid-plane temperatures are lower than the bottom temperature prior to flow of coolingwater $(\sim 8$ a.m.), but when the water starts flowing the mid-plane temperature increases gradually to values above bottom temperature, until water is cut off again at around 9 p.m. When mid-plane temperature is higher than bottom temperature, heat flows downwards, and vice versa, thus the region below the mid-plane acts a storage zone. The surface temperature is always lower than the mid-plane temperature at inlet, indicating a constant heat flow outwards to the surface.

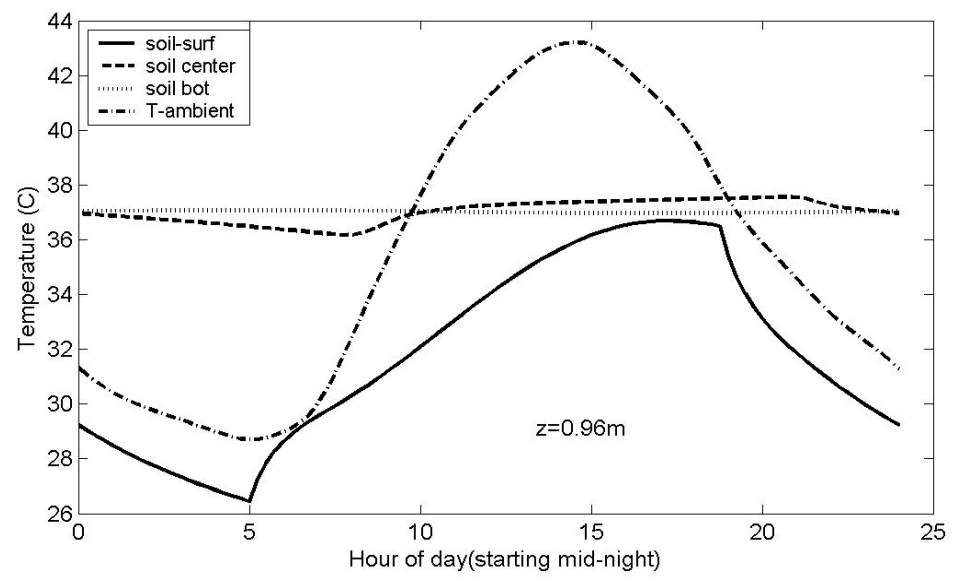

Figure 5: Hourly sink temperatures near inlet section.

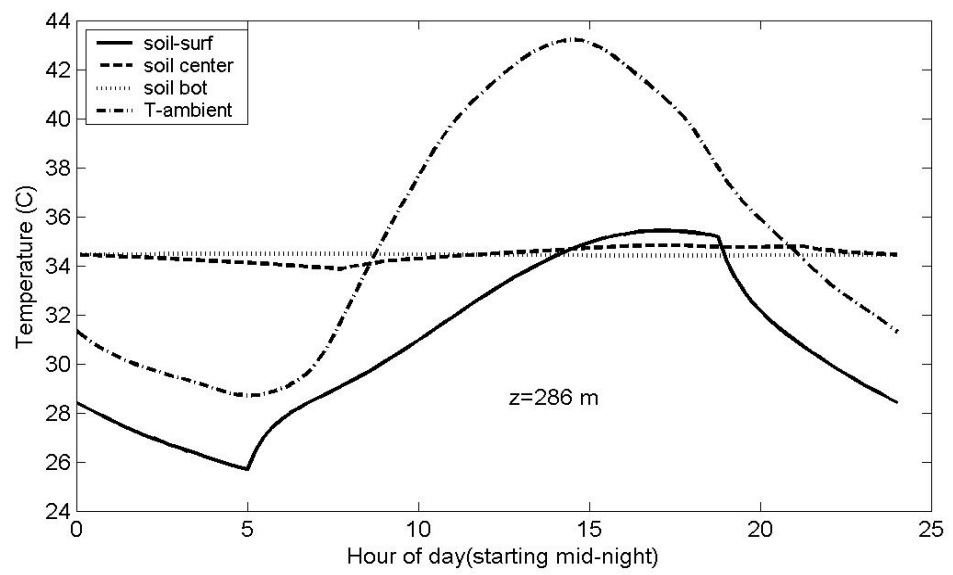

Figure 6: Hourly sink temperatures near exit section. 
Figures 7 and 8 display the corresponding T- $\mathrm{x}$ distribution. A small peak appears at the mid-plane due to the local dispersion of heat by the cooling-water duct. The temperature profile in the bottom one-third of the sink is remarkably uniform, albeit being slightly higher at inlet than at exit section. It therefore could be that a shallower sink would have been adequate.

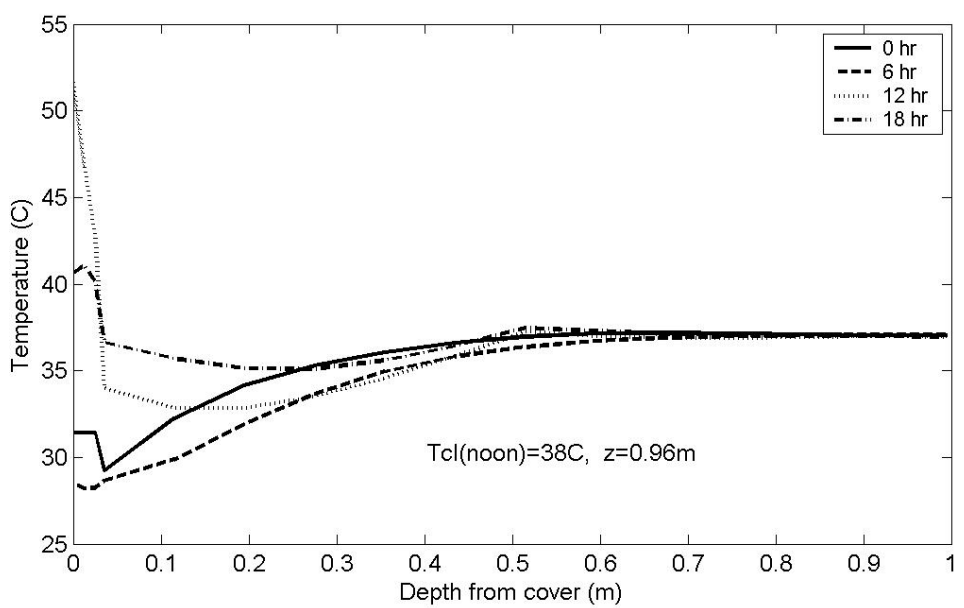

Figure 7: Temperatures within sink at inlet.

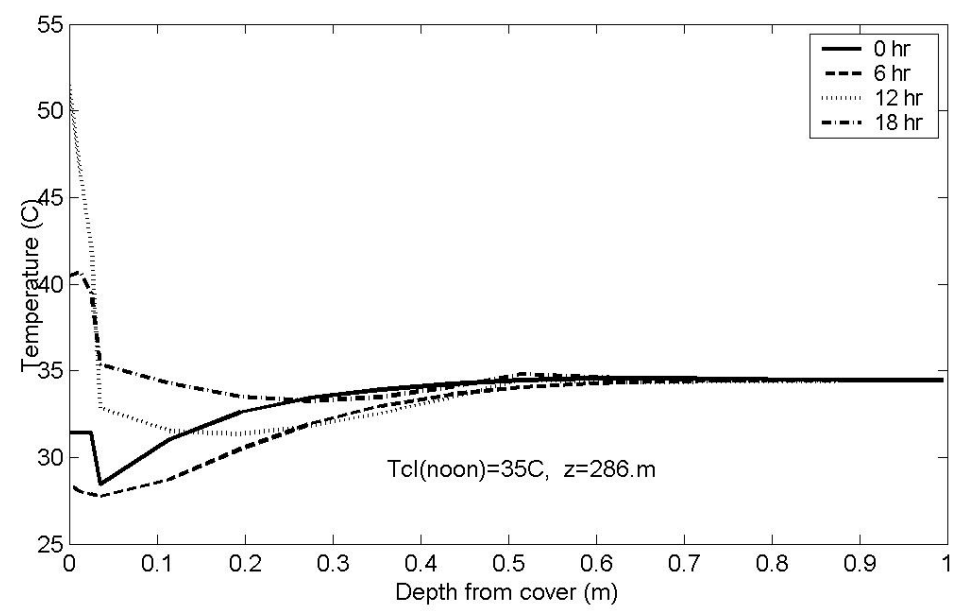

Figure 8: Temperatures within sink at exit.

Figure 9 displays the variation of the cooling water temperature along the centre-line, for three different values of $\mathrm{P}_{\text {eff }}$, representing a single duct without fins, one with average size horizontal fins, and one whose horizontal fins are so large that they may be assumed to spread the dissipated heat uniformly in the 
lateral horizontal direction. The average size is the one adopted for previous displays. The arrows point at the required lengths of duct required to cool water to the desired $35^{\circ} \mathrm{C}$; they range from near $130 \mathrm{~m}$ for full fins, up to near $280 \mathrm{~m}$ for average size fins, and as much as $550 \mathrm{~m}$ for no fins, the sink width being $4 \mathrm{~m}$ in all cases. It is clear that fins are necessary and that they should be designed to be highly effective in order to cut down ground sink size and costs.

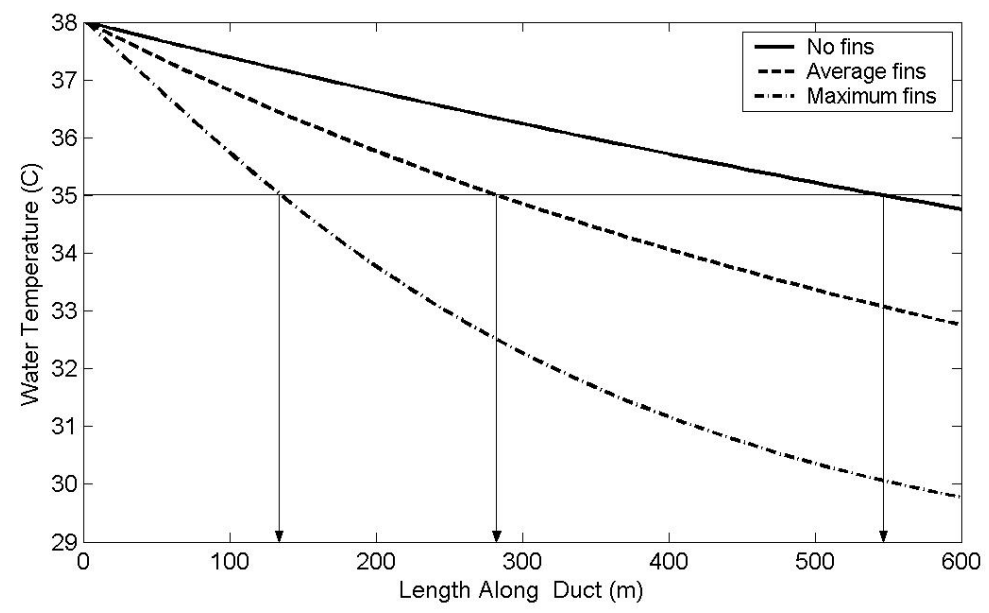

Figure 9: Cooling water temperature distribution.

The total daily condenser cooling load for the demonstration case is $708 \mathrm{~kW} . \mathrm{h} /$ day; of these, approximately $320 \mathrm{~kW} . \mathrm{h} /$ day are born by the ground heat-sink, the remainder being dissipated directly to environment.

\section{Discussion and conclusion}

The paper investigates the performance of a proposed ground heat sink when coupled with the performance of a solar driven air-conditioning system for a ZEH in an exceptionally hot desert environment. The results seem plausible and indicate that such a design is feasible, but requires considerable length of ducting and surface area. Thus it is only attractive were land is cheap and abundant, and where water is scarce and ambient temperatures are too high for direct air cooling; which is the case for most ZEH in remote desert sites. Moreover, the length of the required ducting depends strongly on the effectiveness of duct surface fins. Optimizing fin design however, is not done here as it requires more detailed analysis.

The mathematical model assumes a 24 hour repetition of ambient conditions; since the load calculations are made for the hottest day of the year (employing a $5 \%$ design percentile value), they over predict the ground sink requirements. Under actual operating conditions, a cooler previous day coupled with the high 
thermal capacity of the soil should lead to improve cooling and therefore shorter duct lengths.

Through ignoring the relatively small thermal capacity of the cooling water flowing in the duct, the mathematical model achieves high computational efficiency, by allowing an initial value ordinary differential equation to be solved in the $\mathrm{z}$ direction for cooling water, and a separate partial differential equation to be solved in time and $\mathrm{x}$-direction for the solid material.

\section{Acknowledgement}

This work was sponsored by KAUST under the IDBT project grant held by AUC.

\section{References}

[1] Serag-Eldin, M.A., Thermal design of a modern, air-conditioned, singlefloor, solar-powered desert house, in press, Int. J. of Sustainable Energy, 2011.

[2] Yasukawa, K., Uchida, Y., Tenma, N, Taguchi, Y., Muraoka, H., Ishii, T., Suwanlert, J., Buapeng, S. and Ha, N., Groundwater Temperature Survey for Geothermal Heat Pump Application in Tropical Asia, Bulletin of the Geographical Survey of Japan, vol. 60(9/10), pp. 459-467, 2009.

[3] Permchart, W. and Tanatvanit, S., Study on using ground as a heat sink for a 12,000 Btu/h modified air conditioner, World Academy of Science, Eng. and Technology, 51,pp. 15-18, 2009.

[4] Serag-Eldin, M.A., Modelling the energy systems in a PV powered two floor desert ZEH, accepted for publication in proceedings of CMEM2011, New Forest, UK, May 31-June $2^{\text {nd }}$.

[5] ASHRAE Fundamentals Handbook, 2009, American Society of Heating, Refrigerating and Air-Conditioning Engineers, Inc., USA.

[6] Chinnaraj, C. and Govindarajan, P., Performance Analysis of Electronic Expansion Valve in 1 TR Window Air Conditioner using Various Refrigerants, I. J. of Eng. Sc. and Tech., Vol.2(9),2010, pp. 4020-4025.

[7] Bliss, R.W., Atmospheric Radiation Near the Surface of the Ground: A Summary for Engineers, Solar Energy 59(3), pp. 103-120.

[8] ASHRAE HVAC Applications Handbook, 2007, American Society of Heating, Refrigerating and Air-Conditioning Engineers, Inc., USA.

[9] Kreider, J., Curtis, P. and Rabl, A. 2010, Heating and Cooling of Buildings: Design for Efficiency, McGraw-Hill Inc., New York, p. 47.

[10] Holman, J.P. and White, P., Heat Transfer, $7^{\text {th }}$ edition, McGraw-Hill, 1992. 